\title{
ENFERMAGEM PSIQUIATRICA COMO DISCIPLINA DE GRADUAÇÃO EM ENFERMAGEM NO BRASIL: UMA VISÃO DE CONJUNTO *
}

\author{
Helga Bergold Gross** \\ Lisete Diniz Ribas Casagrande***
}

GROSS, H.B. \& CASAGRANDE, L.D.R. Enfermagem psiquiátrica como disciplina de graduação em enfermagem no Brasil: uma visão de conjunto. Rev. Enf. Esc. USP, São Paulo, $21(3): 225-234$, dez. 1987.

Retrospectiva histórica do ensino da Enfermagem Psiquiátrica, no Brasil, desde a criaf̧ão, em 1890, da primeira Escola de Enfermagem no Hospital de Alienados, no Rio de Janeiro, até o presente, $e$ identificação das tendências atuais desse ensino. enfermagem.

UNITERMOS: Enfermagem psiquiátrica. Ensino de enfermagem. Graduação em

\section{VISĀO DE CONJUNTO DO ENSINO DE ENFERMAGEM PSIQUIATRICA NO BRASIL}

\section{Histórico}

Reportando-nos aos registros históricos do ensino da Enfermagem Psiquiátrica no Brasil, vamos encontrar seu passo inicial em 27 de setembro de 1890 , quando da promulgação do Decreto $\mathrm{n}^{\circ} 791$, que criou no Hospital de Alienados do Rio de Janeiro a primeira Escola de Enfermagem do pais, a qual "se destinava a preparar enfermeiros e enfermeiras para hospicios e hospitais civis e militares" $1,2,3,7,9,10$. O curso tinha duração de dois anos e era exigido do candidato, por ocasião da matricula, que soubesse ler e escrever e conhecesse aritmética elementar. Somente em 1905, foi inaugurada oficialmente esta escola, tendo constado, no primeiro currículo de ensino de Enfermagem no país, a parte de cuidados e tratamentos aos alienados. Anos mais tarde foi ela reorganizada pelo Decreto Lei $n^{\circ}$ 4725/42 e denominada de Escola de Enfermeiros "Alfredo Pinto 7, 10, passando a ter por finalidade, "preparar enfermeiros auxiliares para os serviços sanitários e assistenciais e promover a especialização em serviços psiquiátricos, de enfermeiros diplomados" ?. Após a

* Trabalho apresentado no IV Encontro Nacional de Enfermeiros Psiquiátricos (FiNEP) 09-11/05/84, Londrina, PR.

** Enfermeira e Pedagoga, Mestre em Enfermagem Psiquiátrica pela Escola de Enfermagem de Ribeirăo Preto, Universidade de São Paulo.

*** Pedagoga, Professora Doutora do Departamento de Psicologia e Educaçăo da Faculdade de Filosofia, Ciencias e Letras de Ribeirão Preto, Universidade de São Paulo. 
promulgação da Lei $n^{\circ} 775 / 49$, esta Escola passou a ministrar o curso de Enfermagem. Integra hoje a Universidade do Rio de Janeiro (UNIRIO).

Outra escola surgiu no Rio de Janeiro em fins de 1922, criada pelo Decreto $n^{\circ}$ 15.799/22, com oo nome de Escola de Enfermeiros do Departamento Nacional de Saúde Pública, posteriormente denominada "Ana Nery". No ano seguinte era baixado o Decreto $n^{\circ} 16.300 / 23$, que aprovava o regulamento daquele Departamento, e que regulava o funcionamento da Escola. Embora este não determinasse o número de horas destinado à parte teórica e ao estudo, incluía em seu programa de instrução a "Arte de Enfermeira em Doenças Mentais e Nervosas" 1. Este curriculo era fragmentado em disciplinas de pequena carga horária e de curta duração.

Em 1949, foi promulgada a Lei $n^{\circ} 775$, especifica para o ensino de Enfermagem, regulamentada pelo Decreto $n^{\circ} 27.426 / 49$. Este ampliava o currícolo em sua parte teórica, permanecendo, no entanto, bastante fragmentado, incluindo 29 disciplinas, dentre as quais constava no Art. 5", "Enfermagem e Clínica Neurológica e Psiquiátrica", sendo aqui obrigatório o estágio 1.

A partir de 1961, passaram as Escolas de Enfermagem a exigir curso secundário completo como requisito de admissão, o que as colocou definitivamente no nivel superior. Muitas já pertenciam a Universidades. Isto coincidiu com a determinação de currículos mínimos dos cursos superiores, pelo Conselho Federal de Educação (CFE). Pelo Parecer CFE 271/62, foi fixado o de Enfermagem, estabelecendo-se, então, oito matérias obrigatórias, entre as quais a Enfermagem Psiquiátrica ${ }^{1}$.

Devido à Reforma Universitária ocorrida durante a década subseqüente, tornou-se necessária a revisão de todos os currículos mínimos de cursos superiores, a que não se furtou a Enfermagem. Pelo Parecer CFE 163/72, que fixou os minimos de conteúdo e de duração do "Curso de Graduação em Enfermagem e Obstetrícia", vê-se inserida a disciplina de Enfermagem Psiquiátrica no tronco profissional comum, que leva à graduação do enfermeiro.

Já nos anos 70, surgiram no Rio de Janeiro e em São Paulo, e mais recentemente em Porto Alegre, os primeiros cursos a nivel de Pós-Graduação em "stricto sensu" e "lato sensu", voltados para a área de Enfermagem Psiquiátrica.

Acredita-se ser da mais alta valia a formação pessoal que obtenha cada vez mais preparo, a fim de atuar basicamente em áreas de Saúde Mental, para que, destarte, seja elevado o nivel de assistência de Enfermagem Psiquiátrica em todo o território nacional.

Mais do que nunca, nesta última década, a dimensão das funçōes que o enfermeiro psiquiátrico tem a desempenhar vem se expandindo de forma gradativa. Dependendo do local onde pretenda atuar e da preferência do profissional, são-lhe abertas infinitas opções; pode ele assumir desde o encargo de membro da equipe de um hospital tradicional de 
pessoas com distúrbio mental, onde assume a liderança e presta assistência durante as 24 horas do dia, como pode executar outras funções, segundo a dinâmica das tendências atuais, que é abordada a seguir.

\section{Tendências atuais do ensino de Enfermagem Psiquiátrica}

Nosso século vem se destacando por inúmeras e vertiginosas mudanças. A raça humana se encontra hoje em nova fase da História, onde se verificam alteraçōes profundas e rápidas que emergem, difundindo-se por todo o globo terrestre. A alteração é tão repentina que por vezes, chega a ser alarmante! $\mathrm{E}$ como se não bastassem as mudanças que se operam no cenário terrestre, há preocupação com a vida em outros planetas e com a vida nas profundezas oceânicas!

Os progressos técnico-científicos nos induzem a informaçōes jamais concebidas. As ciências bio-psicossociais, como outras, têm permitido ao homem obter conhecimento de si mesmo e de suas relaçóes com os demais. O espírito científico tem transformado o ambiente cultural e a maneira de pensar e agir dos seres humanos.

Após revisão bibliográfica de inúmeros artigos e trabalhos voltados para este tema, de procedência não só nacional como estrangeira, e após vivência de mais de uma década na Enfermagem, podemos observar o surgimento de algumas tendências relativas ao ensino da disciplina de Enfermagem Psiquiátrica, que não se atêem apenas a esta, mas fazem parte de todo o elenco de disciplinas ministradas nas Escolas de Enfermagem. Muitas das características destas tendências se harmonizam com os recursos, coadunam-se com as necessidades e requererão, sem dúvida, mudanças fundamentais no conceito desta disciplina tanto na prática como no ensino.

Como primeira tendência podemos assinalar que, em face destes notórios avanços da ciência, começamos a ter a pretensão de alcançar, com a assistência de Enfermagem Psiquiátrica, um número cada vez maior de individuos. Notamos também uma ânsia, por vezes até desordenada, de ampliar conceitos inovadores e empregar métodos científicos e tecnológicos que promovam a saúde, previnam e tratem enfermidades.

Como segunda tendência, verificamos um aumento populacional com crescente predominância das extremidades no seu ciclo vital. Aqui os profissionais que atuam principalmente nas áreas de Saúde Mental e Psiquiatria cada vez mais se defrontam com o dever de satisfazer às necessidades de saúde em todas as fases do crescimento e desenvolvimento do individuo, desde a concepção até a morte; atuam, junto a crianças sadias, inclusive as superdotadas e as incapacitadas; junto aos adolescentes, jovens, adultos em todas as atividades da vida, bem como junto aos de meia-idade e convivem com a senectude. Têm eles procurado a participação cada vez maior deste mesmo usuário, no planejamento, execução e avaliação dos serviços de saúde, objetivando maiores benefícios para todos. 
Conseqüentemente, como terceira tendência, nota-se uma clara inevitabilidade da extensão de cobertura, na prestação da assistência de saúde, com ênfase no planejamento, realização e avaliação de ações de prevenção em seus três niveis; para tanto faz-se necessário mobilizar os recursos individuais e coletivos, dentro da comunidade, a fim de que contribuam para a obtenção de melhores níveis de saúde da população.

A quarta tendência está voltada para o seguinte fato: uma vez que se tenha de planejar, executar e avaliar ações de prevenção de saúde em seus três niveis, com ênfase na prevenção primária, é evidente a necessidade do emprego de maior número de profissionais atuantes na área, para que possa ser dado melhor atendimento aos reclamos desta populaçäo.

Se é requerida a atuação do maior número de profissionais de saúde, com o intuito de prestarem assistência de Saúde Mental a indivíduos, famílias e comunidade, surge uma quinta tendência, referente à urgência das Escolas de Enfermagem formarem enfermeiros sem especializaçōes prematuras, um generalista; este, para tanto, precisa estar capacitado a solucionar problemas, ter habilidade para lidar com situações da prática profissional, compreender o limite do potencial de sua própria capacidade e a do indivíduo ou grupo com o qual esteja lidando e promover a manutenção de saúde, prevenção da doença e a assistência ao cliente e a sua reabilitação, seja qual for o ambiente onde exerça a profissão.

Em vista de todas estas transformações que se vêm sucedendo, decorre ainda outra tendência, que é a de aliar a teoria à prática. $\mathrm{Na}$ atividade diária, cada vez mais se processa o reajuste das funções do pessoal engajado na saúde, para atender às transformações; no entanto, poucos são os programas acadêmicos que preparam os enfermeiros para participar e assumir as novas funções emergentes dentro dos planos nacionais de saúde. $\mathrm{E}$ preciso, agora, encontrar um diagnóstico definido das necessidades e prestação de cuidados, in loco, a indivíduos, famílias e grupos que manifestem necessidades idênticas, seja na fase sadia da existência, seja na fase aguda ou em estados crônicos estabilizados da doença.

Segue-se ainda outra tendência, que é a do enfermeiro integrar-se cada vez mais com outros profissionais ou ocupacionais, na comunidade, ao planejar, executar e avaliar as atividades desenvolvidas; é evidente, portanto, a necessidade deste incorporar continuamente novos conhecimentos e técnicas interdisciplinares. Para que isto se torne realidade, é preciso educação continuada, que se faz basicamente através de Pós-Graduação, em "strito sensu" (Mestrado e Doutorado) e "lato sensu" (residência e especialização), o que, em parte, já começa a solucionar a carência de profissionais mais habilitados para o desempenho da função.

Como última tendência, mas não menos importante, observa-se que, aumentou grandemente o número de alunos nos cursos de Enfermagem, fato que exigirá maior número de enfermeiros docentes. Estes, por sua vez, necessitarão de mais preparo, não só quanto ao conteúdo desta dis- 
ciplina, mas quanto ao processo ensino-aprendizagem, para, assim coordenar a tríplice função: docência. serviço e pesquisa.

Em relação à docência de Enfermagem Psiquiátrica, já foi mencionada a necessidade de educação continuada, mas é preciso que esta não se atenha apenas ao ensino acadêmico; convém que sejam realizados outros cursos de complementação, e que sejam assessorados programas educativos em vários níveis. A troca de experiências de ensino dos docentes com outras áreas também é válida, devendo eles contribuir, ainda, de forma isolada ou coletivamente, em programas de educação em serviço, educação em autocuidado e facilitar a integração docente-assistencial.

Quanto ao serviço, deve o enfermeiro psiquiátrico não apenas se interessar por atividades próprias do exercício da profissão como, também, relacionar-se com outras instituiçōes de saúde, participar de movimentos de classe, e procurar propiciar bom relacionamento entre 0 pessoal docente, discente e o de serviços.

A estrutura, quer do ensino quer do serviço de Enfermagem Psiquiátrica, no entanto, deve ser flexível, a fim de facilitar a pesquisa, de tal forma que, seja ela individual ou coletiva, reúna os aspectos preventivos, educativos e os curativos. E, então, o compromisso deste profissional engajado na pesquisa é de não conservar só para si, para o grupo ou instituição os resultados, mas facilitar que sejam eles publicados, difundidos e reutilizados pelo público ao qual se destinam.

3. Conceitos básicos de Saúde Mental, Psiquiatria e Enfermagem Psiquiátrica

Para exercer a "ciência e arte" da Enfermagem Psiquiátrica, busca-se o seu embasamento nas ciências físicas, biológicas e sociais do comportamento. Partindo-se dessa premissa, foram selecionados alguns conceitos importantes, que podem ser considerados como marco de referência para o ensino e exercício da especialidade. Foram adotados entre outros os seguintes:

Saúde Mental: " $\mathrm{E}$ a condição da vida humana que gera desenvolvimento intelectual, emocional e social hamônico do individuo, desenvolvimento este que se caracteriza por uma conduta orientada para a aquisição de bem-estar subjetivo e objetivo, pessoal e coletivo, através da realização de suas potencialidades, contribuindo para os processos de mudança do meio ambiente" 8 .

Psiquiatria: Para se achar um conceito sobre Psiquiatria, vários foram os dicionários consultados. Todos os autores praticamente são unânimes em afirmar que Psiquiatria é advinda da fusão de duas palavras gregas: psiquêe mente + iatria = tratamento ou cura $5,11,12,13$; é uma especialidade médica que se preocupa com os distúrbios mentais. $O$ conceito que aqui se pretende adotar é: "Psiquiatria é o ramo da medicina 
que se relaciona com o diagnóstico, tratamento e prevenção de alteraçōes da mente" 6 .

Enfermagem Psiquiátrica: Procurando definur Enfermagem Psiquiátrica, esbarra-se com alguns conceitos a ela ligados e que dizem respeito mais à função e ao papel desempenhado pelo profissional, do que à definição de sua natureza.

TRAVELBEE 14 já levanta este problema, e, após revisão da literatura pertinente, encontrou as seguintes categorias gerais de conceitos: "definições de Enfermagem Psiquiátrica por ubiquação, por crenças que concebem a Enfermagem Psiquiátrica como parte do conjunto de Enfermagem Psiquiátrica como processo e como área de especialidade clínica em si e por si“. Discorre, então, mais pormenorizadamente sobre cada um destes aspectos, citando inclusive a definição da Associação Americana de Enfermeiros, referente à prática de Enfermagem Psiquiátrica*, compreendendo esta especialidade como parte de um todo que é a Enfermagem.

E neste mesmo livro, TRAVELBEE ${ }^{14}$, passa, então, a definir Enfermagem Psiquiátrica como sendo "Um processo interpessoal, mediante o qual a enfermeira ajuda uma pessoa, família ou comunidade, objetivando promover a Saúde Mental, prevenir ou enfrentar a experiência da enfermidade e do sofrimento mental e, se necessário for, contribuir para que se encontre um sentido nestas experiências".

No presente trabalho, adotamos esta definição como sendo a mais viável, visto que se coaduna com o enfoque da prevenção em seus três niveis.

4. Importância da disciplina e sua integração com as demais disciplinas

Inúmeros são os fatores que têm contribuido para que a Enfermagem Psiquiátrica ainda permaneça em posição de incerteza, mesmo inserida no currículo do ensino de Enfermagem: incerteza quando ao que ensinar e sobre qual deve ser o âmago do programa. A nosso ver, a tendência de fazer do enfermeiro um generalista deve se estender também

(*) A Enfermagem Psiquiátrica ê descrita como área especializada da prática, da ciência e da arte da Enfermagem. O caráter cientifico da Enfermagem Psiquíatrica consiste na aplicaçăo de teorias novas e complexas do comportamento humano baseadas nas ciências utilizadas em todos os campos da Enfermagem. A arte da Enfermagem Psiquiatrica se exerce mediante a utilização consciente da própria pessoa na prática da profissão. A Enfermagem Psiquiatrica utiliza, assim, uma ampla gama de conhecimentos e habilidades para abordar situacóes diversas, que implicam em utilizar diferentes enfoques psiquiatricas no cuidado de cada paciente. Mediante estudos sistemáticos do fenomeno clínico, novas teorias stao formuladas e se desenvolvem novas práticas de Enfermagem Psiquiátrica. Ela é um servico prestado a pessoas afetadas por processos intelectuais patologicos e outros transtornos da personalidade, manifestos de tal forma que são impedidas de levar uma vida normpl. A Enfermagem Psiquiátrica possui funçōes e práticas dirigidas no sentido de prevenir ou produzir um impacto corretivo sobre a doenca mental e aspira a promover a Saude Mental 6tima, de todos os individuos, familias e comunjdade. 
ao aluno que passa pela disciplina de Enfermagem Psiquiátrica. Assim ele só será um profissional eficiente à medida em que puder manipular sua informação com precisão, seriedade e extensão.

Este fato, no entanto, não ocorre apenas na Enfermagem Psiquiátrica; evidencia-se também na Psiquiatria, como especialidade médica. Já em 1941, a Comissão de Peritos em Saúde Mental da Organização Mundial de Saúde, informava que "na maioria dos países do mundo, a educação que leva à graduação, tem sido, neste sentido (da Psiquiatria), muito deficiente e mesmo onde o currículo médico abrange certos aspectos da medicina psicológica, geralmente é dada ênfase à descrição das psicoses, ao invés de levar a compreender a gênese, prevenção e tratamento de distúrbios psicossomáticos e psiconeuróticos" ${ }^{15}$.

A história da cura de distúrbio mentais é tão antiga quanto a própria história da humanidade e a maneira como foi ensinada se deveu em grande parte às mudanças dos valores sociais. Os ciclos de prestação de assistência foram extremamente mutáveis através dos séculos. Essa mesma história achou-se ligada ao sobrenatural, ao enclausuramento, ao "hospitalismo" ou simplesmente foi vista como algo de somenos importância.

A Enfermagem, que por séculos, esteve profundamente arraigada à Medicina, levou, em conseqüência, a Enfermagem Psiquiátrica a palmilhar a mesma senda. Por ser incompleta a sua história, não se pode precisar o ponto exato em que se deu a assistência ao doente mental por esta especialidade de Enfermagem, como era de se desejar. Sabe-se que cada época apresentou seus modelos assistenciais, na tentativa de encontrar uma solução válida que mais se adaptasse à necessidade do paciente no momento.

Apesar dos avanços tecnológicos de nosso século e dos marcantes progressos em outras áreas de Enfermagem, é de se salientar que a Enfermagem Psiquiátrica não teve assim um destaque tão notório nestes últimos lustros, como se deveria supor. Tem-se que convir, no entanto, que ela não parou nem no tempo, nem no espaço. Muito tem sido feito e muito resta por fazer ainda! Um dos fatores que a influenciaram mais negativamente talvez tenha sido a pouca atenção dada ao relacionamento existente entre enfermidade e $o$ ambiente. Tem sido negligenciada a influência social (que recebe várias denominações, como ambiental, interpessoal, familiar, cultural, ocupacional e até ecológica, e outros potentes fatores externos) sobre o estado de perfeito equilibrio, cuja alcunha é saúde, e sobre uma antagônica distorção patológica cognominada enfermidade. $O$ ser humano isolado, ou em grupo, não pode ficar alheio ao ambiente no qual se acha inserido; a verdade é que suas atividades, sua conduta e sua sobrevivência andam de mãos dadas com a realidade onde ele cresce e se desenvolve.

O que não se pode deixar de mencionar, e com marcante relevância, é a contribuição de vasto alcance que os avanços ocorridos na área de Saúde Pública e da Medicina Preventiva vêm dando à especialidade psiquiátrica; além de haverem desempenhado eficiente papel no cenário 
mundial, com a diminuição de graves enfermidades transmissíveis e de outras de origem ocupacional, melhorias ambientais, nutricionais e de educação em saúde, aqueles avanços agora ultrapassam suas fronteiras e começam a ser adotados pela Enfermagem Psiquiátrica. A ótica dos profissionais daquelas áreas vai sendo ampliada e verifica-se que, além dos muros de instituições e mesmo do confinamento em leitos hospitalares, existe a promoção da saúde e a prevenção de moléstias; que as pessoas podem aprender a conviver com o paciente psiquiátrico como ser humano, da mesma forma pela qual se convive com os portadores de quaisquer enfermidades. Passa-se agora por uma fase de transição, cujo questionamento não é mais se o paciente apresenta um diagnóstico ou um conjunto deles - ou quais destes componentes pode ser identificado como desencadeante: cerebral? geral- endócrino? psicopatológico? tóxico infeccioso? e sim, quais os fatores e condições que afetam o estado de saúde do paciente. Os profissionais de Enfermagem Psiquiátrica começam a dar ênfase também a atividades educativas, preventivas e terapêuticas e não mais somente às ligadas ao tradicional modelo médico; partem agora para a busca do seu próprio modelo.

Prevê-se pela prática da Saúde Mental, na atualidade, que a Enfermagem Psiquiátrica não será mais privativa de especialistas, pois se chegou à conclusão de que seu conteúdo ultrapassa os limites de qualquer disciplina isolada. Na realidade, dever-se-ia integrar o ensino de Saúde Mental em todas as áreas de saúde e partir, assim, para a eliminação de especialização exclusiva, e então analisar o paciente de forma "holistica".

Conforme se mencionou no início, não existe ainda, na atualidade, consenso referente ao conteúdo específico quanto ao ensino de Enfermagem Psiquiátrica a ser dado nas Escolas de Enfermagem: acredita-se que jamais se chegue a ele. Inúmeros fatores podem servir de pretexto.

Segundo FERNANDES 4, "algumas das causas dessa situação fundamentam-se não só na relação do ensino com a estrutura social, mas também no fato de que as instituições escolares não respondem automaticamente ao projeto definido pela politica educacional, isto é, os professores, na sua grande maioria, não cedem, na prática, em benefício do ensino dos aspectos preventivos e sociais, senão em espaços de tempo muito limitados".

Outro fator, também desencadeante, mencionado pela mesma autora, é que "a assistência psiquiátrica tem sido de má qualidade, precária e insuficiente para a grande maioria da população, como também tem sido caracterizada, com ênfase no modelo hospitalar, por uma prática repressiva, cronificadora e estigmatizante que pode ser traduzida por uma técnica antiterapêutica que não atende às necessidades do doente" 4 .

Situa-se também como uma das causas bem marcantes, o ensino tradicional que tem levado os alunos da maioria das escolas da área de saúde, a se alienarem da ótica do ser humano como um todo. Preparam-se profissionais de saúde como se fossem mecânicos ou engenheiros para 
das assistência a máquinas, ou quando muito, veterinários, para cuidar de animais, quando, na verdade, o que se espera é o preparo de alunos para atuarem em benefício da saúde de seres humanos.

Para que esta disparidade comece a ser sanada, chega-se a pensar em que Enfermagem Psiquiátrica poderia ser o elo de ligação com as demais disciplinas, visto que se começa a valorizar agora o relacionamento do individuo, como um todo (o seu ambiente social, suas reações emocionais e personalidade), com a doença.

Assim, quando se atua em diferentes programas de saúde, como profilaxia do parto (Enfermagem Materno-Infantil), preparo da familia para enfrentar a morte (Enfermagem Médico-Cirúrgica, quem sabe Gerontológica ou mesmo Pediátrica), que são consideradas atividades de saúde, desenvolvidas no contexto do amplo ciclo vital, estas englobam concomitantemente os aspectos emocionais do individuo. Quando se presta assistência a paciente cirúrgico, deve-se saber exatamente como lidar com ele, a fim de evitar sofrimento desnecessário e ajudá-lo a enfrentar aquele momento com galhardia. Se é medicação que se oferece a um paciente com problemas gastrointestinais, melhor fora que se lhe permitisse falar de sua vivência, do que simplesmente entulhá-lo com medicamentos.

Por estas e muitas outras razōes, urge que se apele para a melhoria do ensino da Enfermagem Psiquiátrica, quer teórico, quer prático, ao alunado de graduação; esta é a única maneira de capacitá-lo a distinguir a complexidade da etiologia das enfermidades e a dar relevância a situações emocionais e sociais, nas quais os individuos com quem entra em contato acham-se imersos; esta é também a maneira de habilitar o estudante a ampliar o conceito de seu futuro papel como profissional e a enfrentar sua responsabilidade enquanto pessoa, em face do ser humano como pessoa.

Numa abrangência maior, dois podem ser os tipos de curriculos que uma Escola de Enfermagem podem apresentar: o primeiro será mantendo a Enfermagem Psiquiátrica como disciplina isolada, dando-lhe, porém, abertura e favorecendo compreensão mais ampla do individuo, baseada na visão "holística".

O segundo tipo será de reestruturar todo o currículo, promovendo fusão de todas as disciplinas, inclusive de Enfermagem Psiquiătrica e que sejam estudados concomitantemente o desenvolvimento do ser humano através de seu ciclo vital, ou o ciclo saúde-enfermidade, onde se focalizem aspectos de promoção, proteção, recuperação e reabilitação da saúde.

GROSS, H.B. \& CASAGRANDE, L.D.R. The teaching of Psychiatry Nursing to undergraduate students in Brazil. Rev. Esc. Enf. USP, São Paulo, 21(3):225-234, Dec. 1987.

Historical retrospective of the teaching of Psychiatric Nursing in Brazil, in a Psychiatric Hospital of Rio de Janeiro, since the openning, of the first School of Nursing, until the present. The authors also try to identify the new concepts of this nursing speciality and the new trends of teaching it to undergraduate students.

UNITERMS: Psychiatric nursing. Education, mursing. Education, nursing undergraduate. 


\section{REFERÊNCIAS BIBLIOGRÅFICAS}

1. CARValho, A.C. Orientaçăo e ensino de estudantes de enfermagem no campo clínico. Săo Paulo, 1972. 126p. (Tese de doutoramento - Escola de Enfermagem da USP).

2. Associaçio Braslleira de Enfermagem, 1926/76: documentário. Rio de Janeiro. Folha Carioca, 1976. 514p.

3. CASTRO, I.B. et alil. Modificacões da imagem da enfermejra percebidas pelos estudantes, durante o curso de graduação de enfermagem. Rev. Bras. Ent., Rlo de Janeiro. $27(2): 532,1974$.

4. FERNANDES, J.D. Reflexão sobre a prática do ensino da enfermagem psiquiátrica $\theta$ saúde mental. Bev. Bras. Enf., Brasilia, 32(4):403-6, 1979.

5. FORTes, H. \& PACheCo, G. Dicionário médico. Rio de Janeiro, Fabio M. de Mello, 1968. 1139p.

6. MILLER, B.F. \& KEANE. C.B. Encyclopedia and dictionary of medicine and nuraing. Philadelphia, W.B. Saunders, 1972.

7. NIVEL de formação do auxiliar de enfermagem, após a promulgação da Lei no 5.692, de 11 de agosto de 1971: Parecer no 2.713/74 da C.E. $1^{\circ}$ e $2^{\circ}$ graus. hev. Bras. Enf., Rio de Janeiro, 2r(4):532-48, out./dez. 1974.

8. ORganizacion PaNAMERICANA DE LA SALUd. Primer informe del comitê de expertos de la enseñanza de la salud mental en las escuelas de medicina de la America Latina. Educ. Med. $y$ Salud, Washington, 8(4):420-27, 1974.

9. PAIXAO, W. História da enfermagem. 4. ed. Rio de janeiro, Buccini, 1969.

10. PONTES, C. Contribuicão a história da enfermagem - Escola de Enfermagem Alfredo PInto: a ploneira das escolas de enfermagem no Brasil. Rev. Bras. Enf., Rio de Janeiro, 24(3/4):199, 1971.

11. SKINNER, H.A. The origin of medical terms. Baltimore, William \& Wilkins, 1949.

12. SteadmaN's Medical Dictionary. 22. ed. Baltimore, William \& Wilkins, 1949.

13. Szakely. L. e B. Diccionario enciclopedico de la psique. 5. ed. Buenos Aires, Claridad, 1972.

14. TRAVELBEE, J. Intervención en enfermeria peiquíatriea. Carvajal, Organización Panamericana de la salud, 1979. 257p.

18. WORLD HEALTH ORganization. Expert Commiteo on mental health, apud: LIN, T. Porspective in the tesching psychiatry. Genebra, World Health Organization, 1961, p.23-59. (Public Hoalth Papera).

Recebldo para publicaçáo em 2-9-86.

Aprovado para publicação em $15-12-87$ 